\title{
Fine Needle Aspiration Biopsy of Thyroid Nodules in Children and Adolescents
}

\begin{abstract}
Thyroid nodules are uncommon in children and adolescents compared with adults, but the risk of malignancy is much higher. In adults, fine needle aspiration biopsy (FNAB) has been used extensively to select patients for surgical exploration with a high degree of reliability. The purpose of this study was to assess the utility of FNAB for the management of thyroid nodules in children and adolescents. We reviewed our experience with 60 FNABs of thyroid nodules in 51 children and adolescents. Of the 60 aspirates, 45 aspirates (74\%) were diagnosed as "benign", 5 aspirates $(8 \%)$ as "suspicious for malignancy", and 6 aspirates (10\%) as "malignant", and 4 aspirates (7\%) as "unsatisfactory". Thyroidectomy was performed in 17 patients, and 5 with a cytological diagnosis of "benign" revealed nodular hyperplasia in three and follicular adenoma in two; 5 with a cytological diagnosis of "suspicious" revealed nodular hyperplasia in one, follicular adenoma in two, and papillary carcinoma in two; and 6 with a cytological diagnosis of "malignant" revealed papillary carcinoma. One patient with a cytological diagnosis of "unsatisfactory" revealed papillary carcinoma. The diagnostic accuracy was $81 \%$ with $100 \%$ sensitivity and $63 \%$ specificity. The positive and negative predictive values of FNAB were $73 \%$ and $100 \%$, respectively. We conclude that FNAB is a good screening test for thyroid nodules in children and adolescents because of its high sensitivity.
\end{abstract}

Key Words : Thyroid Gland; Thyroid Nodule; Biopsy, Fine-Needle; Child; Adolescent

\author{
Sun Hee Chang ${ }^{*, \dagger}$, Mee Joo ${ }^{*, \dagger}$, \\ Hanseong Kim
}

Clinical Research Center* and Department of

Pathology ${ }^{\dagger}$, Inje University Ilsan Paik Hospital, Goyang, Korea

Received : 21 July 2005

Accepted : 2 December 2005
Address for correspondence
Sun Hee Chang, M.D.
Department of Pathology, Inje University Ilsan Paik Hospital, 2240 Daewha-dong, Ilsan-gu, Goyang 411-706, Korea
Tel : +82.31-910-7138, Fax : +82.31-910-7139
E-mail : changsh@ilsanpaik.ac.kr

\section{INTRODUCTION}

Thyroid nodules are uncommon in children and adolescents compared with adults, but the risk of malignancy is much higher (14 to $40 \%$ in children compared with $5 \%$ in adults) (1-3). In adults, fine needle aspiration biopsy (FNAB) has been used extensively for the management of thyroid disease and for patient selection for surgical exploration with a high degree of reliability $(4,5)$. However, FNAB has not been utilized extensively for the evaluation of thyroid nodules in the young; and relevant data in the literature are often in disagreement (2, 6-10). To assess the utility of FNAB for the management of children and adolescents, we reviewed our experience with FNAB for thyroid nodules in children and adolescents.

\section{MATERIALS AND METHODS}

The reports of thyroid FNAB performed in 51 children and adolescents at the Inje University Ilsan Paik Hospital were reviewed. Eighty one percent of the procedures were performed by three cytopathologist, using 23 gauge needles connected to $10 \mathrm{~mL}$ syringes. In these cases, cytological materi- al was smeared immediately onto slides. Some of the slides were air dried and stained with Diff-Quik stain for an immediate evaluation of specimen adequacy. Other slides were immediately alcohol-fixed and stained with Papanicolaou stain. The remaining procedures were performed by radiologists. All of these slides were alcohol-fixed and sent to our laboratory for staining and evaluation. FNAB results were classified into three categories: 1) malignant, when the aspirates had unequivocal cytological findings of malignancy; 2) suspicious for malignancy, including follicular neoplasms and aspirates that showed some features of papillary carcinoma, e.g., a few cells with intranuclear inclusions or nuclear grooves but without sufficient criteria for a definitive diagnosis of malignancy; and 3) benign, including nodular hyperplasia, colloid cyst, and thyroiditis. Aspirates with less than at least six clusters of well preserved follicular cells on two slides were considered unsatisfactory (11).

\section{RESULTS}

Fifty-one children and adolescents underwent FNAB, and a total of 60 FNABs were performed on these patients. Pa- 
tients' ages ranged from 2 to $21 \mathrm{yr}$ with a mean age of $17 \mathrm{yr}$. Sixteen $(27 \%)$ of the patients were 2 to $15 \mathrm{yr}$ old. Thirty-eight $(75 \%)$ were female and thirteen $(25 \%)$ were male. Cytological findings are summarized in Table 1 and 2. Forty-five (74\%) of the aspirates were diagnosed as "benign". The cytological diagnosis in three cases was Hashimoto's thyroiditis. Five $(8 \%)$ of the aspirates were diagnosed as "suspicious for malignancy". Four of these aspirates were further diagnosed as follicular neoplasm and one was suspicious for papillary carcinoma. Six (10\%) of the aspirates were diagnosed as "malignant" and further diagnosed as papillary carcinoma. Four (7\%) of the aspirates were "unsatisfactory" (Table 1).

The surgical outcomes of 17 patients who underwent thyroidectomy are summarized in Table 3 . Of 5 patients with a cytological diagnosis of "benign", three had nodular hyperplasia and two follicular adenoma. Of 4 patients with a cytological diagnosis of "follicular neoplasm", one had nodular hyperplasia, two had follicular adenoma, and one papillary carcinoma. One patient with a cytological diagnosis of "suspicious for papillary carcinoma" had papillary carcinoma. All 6 patients with a cytological diagnosis of "malignant" revealed papillary carcinoma. One of 4 patients with a cytological diagnosis of "unsatisfactory" underwent surgery and was found to have papillary carcinoma. Other cases were followed up clinically without surgical intervention (Table 2).

The cases "suspicious" or "malignant" by cytological diagnosis that were found to have a malignant lesion at surgery were considered "true positive." "True negative" cases comprised cases considered "benign" with a benign lesion, including follicular adenoma, on resection. Using these criteria, the diagnostic accuracy of FNAB was $81 \%$ with a sensitivity of $100 \%$ and a specificity of $63 \%$. Positive and negative predictive values were $73 \%$ and $100 \%$, respectively, and false negative and positive values were $0 \%$ and $37 \%$, respectively.

Three false positive cases were diagnosed as "follicular neoplasm" on FNAB but revealed nodular hyperplasia or follicular adenoma on surgical resection. The cytological findings of these cases were the presence of syncytial fragments, a microfollicular pattern, and nuclear grooves (Fig. 1). Two of 5 true negative cases revealed follicular adenoma on surgical resection. These cases showed some clusters of atrophic follicular epithelial cells and a few scattered macrophages in the bloody background (Fig. 2).

Table 1. Cytological diagnoses by fine needle aspiration biopsy

\begin{tabular}{lccc}
\hline \multirow{2}{*}{$\begin{array}{l}\text { Diagnostic } \\
\text { category }\end{array}$} & $\begin{array}{c}\text { Age group } \\
\text { 2-15 yr old } \\
(\%)\end{array}$ & $\begin{array}{c}16-21 \mathrm{yr} \text { old } \\
(\%)\end{array}$ & $\begin{array}{c}\text { No. of cases } \\
(\%)\end{array}$ \\
\hline Malignant & $2(13 \%)$ & $4(9 \%)$ & $6(10 \%)$ \\
Suspicious & $1(6 \%)$ & $4(9 \%)$ & $5(8 \%)$ \\
Benign & $13(81 \%)$ & $32(73 \%)$ & $45(74 \%)$ \\
Unsatisfactory & $0(0 \%)$ & $4(9 \%)$ & $4(7 \%)$ \\
Total & 16 & 44 & 60 \\
\hline
\end{tabular}

\section{DISCUSSION}

In adults, FNAB has become a part of the routine evaluation of thyroid nodules. Since its introduction, the percentage of patients that undergo thyroidectomy has decreased by $25 \%$ to $50 \%$ with the use of FNAB (6). But FNAB has been underutilized for the evaluation of thyroid nodules in the young because of the possibility of complications and the need for sedation. In our practice, sedation is rarely required and no complications have arisen. In our opinion, FNAB is a relatively simple procedure with few complications.

Internal and external reports of predominantly adult patients with thyroid nodules show that the sensitivity of thyroid FNAB ranges from $80-100 \%$ with a specificity of 90 $100 \%$ (3-5, 12-15). Investigations of FNAB in pediatric thyroid nodules have shown a wide range of sensitivities (7-10). Degnan et al. (7) reported on 18 children who underwent surgery after thyroid FNAB and found a sensitivity of $50 \%$. Similarly, Lugo-Vicente et al. (8) reported on 24 children who underwent thyroidectomy for thyroid nodules, and a retrospective review of the cytological materials of 18 cases that received preoperative thyroid FNAB revealed a sensitivity of $60 \%$. Thus, because of its apparent low sensitivity, they concluded that FNAB did not have a primary role in surgeon's decision regarding the surgical management of these patients. However, Corrias et al. (9) reported on 42 children who underwent surgery after thyroid FNAB and found a sensitivity of $95 \%$. Moreover, Amrikachi et al. (10) reported a sensitivity of $100 \%$ in 218 child and adolescent thyroid aspirates. In the present study, we also achieved a sensitivity of $100 \%$. These better results are similar to those obtained in adults and suggest that FNAB is highly effective at selecting patients for surgery without missing malignant lesions.

The reported specificities of thyroid FNAB in pediatric thyroid nodules ranges from 65 to $90 \%$ (7-10). In our study, its specificity of $63 \%$ was lower than usual. The one cause of low specificity might be associated with statistical problem. Amrikachi et al. (10) suggested that because most cases with a negative FNAB result were followed up clinically, it was difficult to estimate the true negative diagnosis in the follow-

Table 2. Relation between cytological diagnosis and histological diagnoses of resected thyroid nodules in children and adolescents

\begin{tabular}{lcccc}
\hline & \multicolumn{3}{c}{ Histological diagnoses } & \\
\cline { 2 - 4 } Cytological diagnosis & $\begin{array}{c}\text { Nodular } \\
\text { hyperplasia }\end{array}$ & $\begin{array}{c}\text { Follicular } \\
\text { adenoma }\end{array}$ & $\begin{array}{c}\text { Papillary } \\
\text { carcinoma }\end{array}$ & Total \\
\hline Malignant & 0 & 0 & 6 & 6 \\
Suspicious for & 0 & 0 & 1 & 1 \\
$\quad$ papillary carcinoma & & & & \\
Follicular neoplasm & 1 & 2 & 1 & 4 \\
Benign & 3 & 2 & 0 & 5 \\
Unsatisfactory & 0 & 0 & 1 & 1 \\
Total & 4 & 4 & 9 & 17 \\
\hline
\end{tabular}




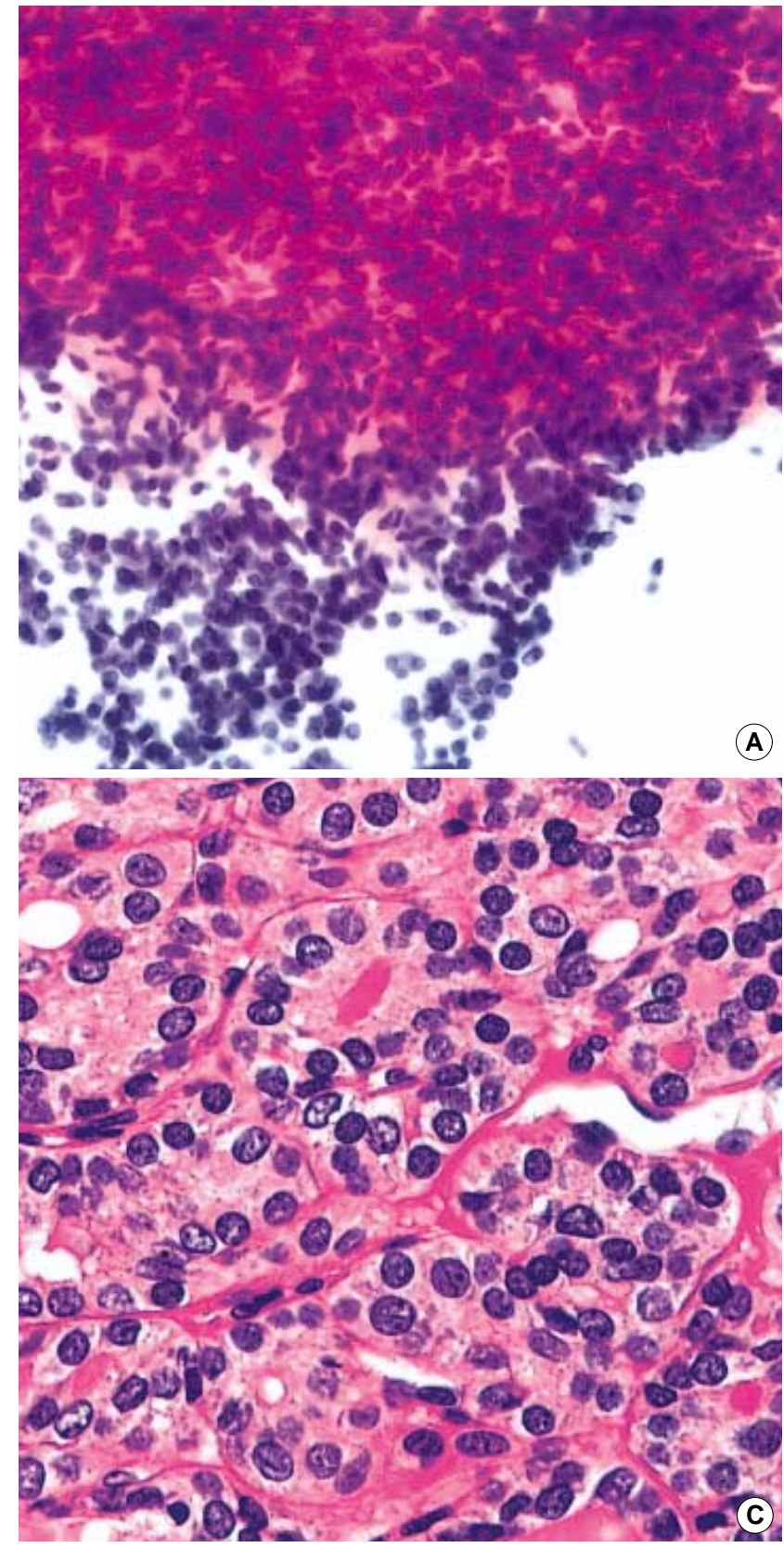

up group. If this group were considered true negative in the present study, specificity increases to $94 \%$. Another statistical problem concerns the precise definition of false positive and false negative. In our studies, for statistical analysis, cases with a suspicious or malignant cytological diagnosis that had a malignant lesion at surgery were considered true positives $(9,10)$. Using these criteria, the sensitivity and specificity of thyroid FNAB were $100 \%$ and $63 \%$, respectively. Follicular adenomas and carcinomas are both neoplastic lesions and their differentiation usually requires surgical excision and examination of entire nodules. Therefore, in some studies, the cases with a cytological diagnosis of suspicious or positive for malignancy and a histological diagnosis of follicular neoplasms en-

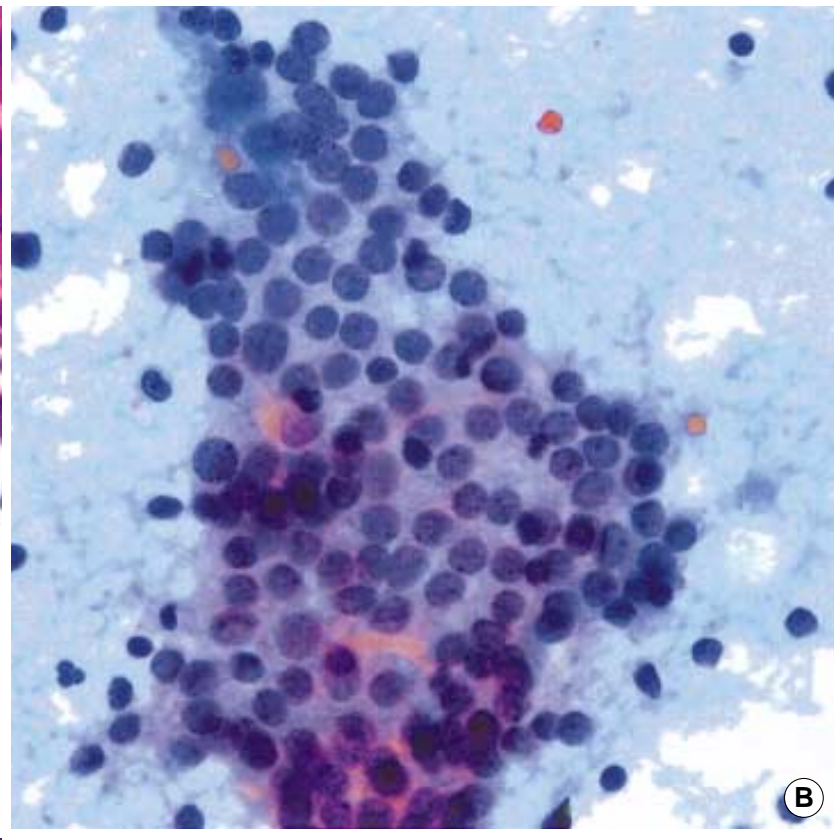

Fig. 1. (A) Fine needle aspiration biopsy finding of follicular neoplasm confirmed as a follicular adenoma. The aspirate shows syncytial fragments (Papanicolaou, $\times 200$ ). (B) The loosely cohesive follicular cells show nuclear grooves (Papanicolaou, $\times 400$ ). (C) On histologic finding, the follicular cells show nuclear grooves $(H \& E, \times 400)$.

compassing both follicular adenoma and follicular carcinoma are considered true positive results. And, using these criteria, the sensitivity and specificity of our study would have been $83 \%$ and $75 \%$.

Even if the statistical problems were considered, the reported specificities including ours had a wide range of figure and were sometimes disappointing. These are due to the existence of follicular neoplasms. Follicular neoplasms have generally been considered a diagnostic "gray zone" in thyroid FNAB. Included in this group are hyperplastic nodules of goiters, follicular adenomas, and follicular carcinomas. Because of overlapping cytologic features, a diagnosis of follicular carcinoma is usually made after examining permanent sections follow- 


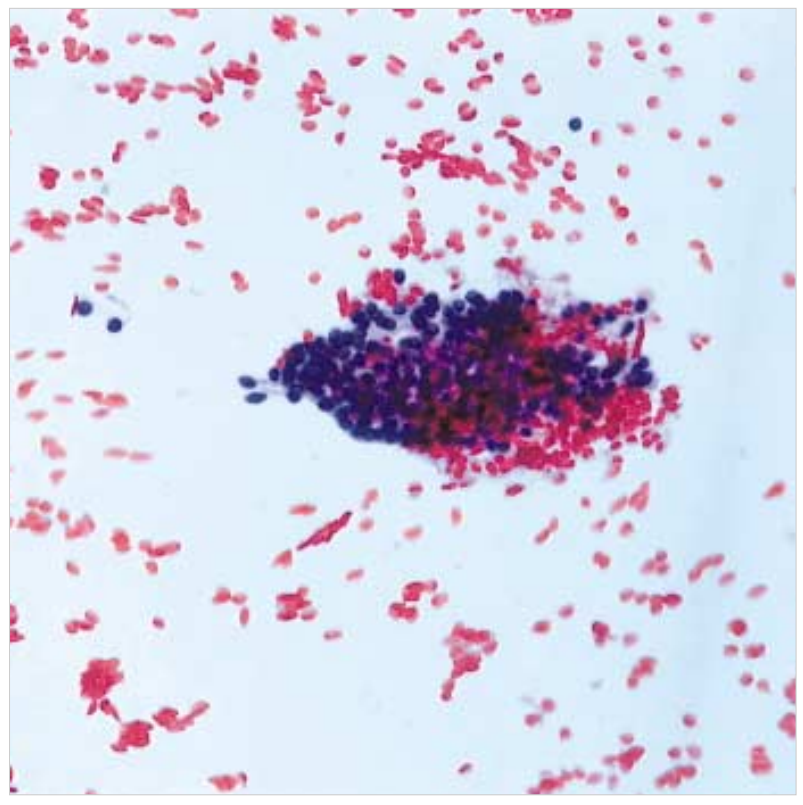

Fig. 2. Fine needle aspiration biopsy finding of nodular hyperplasia confirmed as a follicular adenoma. The aspirate shows loosely cohesive follicular cells in the bloody background (Papanicolaou, $\times 200$ ).

ing surgical treatment. The overall rate of malignancy in nodules with cytological diagnosis of follicular neoplasm has been reported as approximately 20-30\% (16). Kim et al. reported that $50 \%$ of such patients were diagnosed as malignancy, and an age below $20 \mathrm{yr}(77 \%)$ had a significant increased risk for malignancy (16). In the present study, one of four cases with a cytological diagnosis of follicular neoplasm revealed papillary carcinoma. This figure is lower than that of Kim et al. but is similar to the overall rate of $20-30 \%$.

In our false positive cases, the presence of syncytial fragments, a microfollicular pattern, and nuclear grooves misled a cytological diagnosis of follicular neoplasm. The nuclear grooves are a non-specific feature which can be seen in cases of Hashimoto's thyroiditis, nodular hyperplasia with oncocytes, follicular adenoma, or Hurthle cell adenoma (5). Of five present cases with a cytological diagnosis of benign, two cases were histologically diagnosed as follicular adenoma. These cases showed some clusters of atrophic follicular epithelial cells and a few scattered macrophages in the bloody background. Yang et al. suggested the most important clue in differentiating follicular neoplasm from nodular hyperplasia was "abundant blood containing microfollicles" (17). However, macrofollicular adenomas have far lower microvessel density than microfollicular nodules because the space occupied by the large colloid lakes are devoid of blood vessels. Therefore, macrofollicular adenomas will be diagnosed as nodular hyperplasia by FNAB. Likewise, a discrete but unencapsulated microfollicular nodule will be diagnosed as "follicular neoplasm" by FNAB, resulting in the excision of nonneoplastic nodules.

Some reports have suggested that the cases diagnosed as follicular neoplasm on thyroid can be stratified into lesions with a high risk of malignancy and with a low risk of malignancy that can be managed by clinical observation alone on the basis of clinical characteristics such as large size of the index nodule (lesions measuring $3 \mathrm{~cm}$ or larger) and male sex (18). However, we experienced that one papillary carcinoma of a cytological diagnosis of follicular neoplasm was female and her thyroid nodule measured $1.8 \mathrm{~cm}$ in diameter. In another three cases revealed follicular adenoma or nodular hyperplasia, the ratio of male:female was 1:2 and their nodule measured $3.3 \mathrm{~cm}$ to $3.4 \mathrm{~cm}$ in diameter. Although clinical characteristics can help in selecting patients for surgery, the final diagnosis by histological examination is needed. Several reports have suggested that the use of immunohistochemical markers such as cytokeratin-19, galectin-3, and HBME-1 are useful in FNAB specimens of the thyroid to differentiate between benign and malignant lesions (19-21). But some benign thyroid nodules can also stain with these markers.

We concluded that FNAB is a good screening test for thyroid nodules in children and adolescents because of its high sensitivity. However, the additional use of various clinical variables and immunohistochemical markers can be helpful to differentiate in follicular neoplasms in FNAB.

\section{REFERENCES}

1. Hung W, Anderson KD, Chandra RS, Kapur SP, Patterson K, Randolph JG, August GP. Solitary thyroid nodules in 71 children and adolescents. J Pediatr Surg 1992; 27: 1407-9.

2. Yip FW, Reeve TS, Poole AG, Delbridge L. Thyroid nodules in childhood and adolescence. Aust N Z J Surg 1994; 64: 676-8.

3. Amrikachi M, Ramzy I, Rubenfeld S, Wheeler TM. Accuracy of fine needle aspiration of thyroid. Arch Pathol Lab Med 2001; 125: 484-8.

4. Castro MR, Gharib H. Thyroid fine-needle aspiration biopsy: progress, practice, and pitfalls. Endocr Pract 2003; 9: 128-36.

5. Ylagan LR, Farkas T, Dehner LP. Fine needle aspiration of the thyroid: a cytohistologic correlation and study of discrepant cases. Thyroid 2004; 14: 35-41.

6. Khurana KK, Labrador E, Izquierdo R, Mesonero CE, Pisharodi LR. The role of fine-needle aspiration biopsy in the management of thyroid nodules in children, adolescents, and young adults: a multi-institutional study. Thyroid 1999; 9: 383-6.

7. Degnan BM, McClellan DR, Francis GL. An analysis of fine-needle aspiration biopsy of the thyroid in children and adolescents. J Pediatr Surg 1996; 31: 903-7.

8. Lugo-Vicente H, Ortiz VN, Irizarry H, Camps JI, Pagan V. Pediatric thyroid nodules: management in the era of fine needle aspiration. $J$ Pediatr Surg 1998; 33: 1302-5.

9. Corrias A, Einaudi S, Chiorboli E, Weber G, Crino A, Andreo M, Cesaretti G, de Sanctis L, Messina MF, Segni M, Cicchetti M, Vigone M, Pasquino AM, Spera S, de Luca F, Mussa GC, Bona G. Accuracy of fine needle aspiration biopsy of thyroid nodules in detecting malignancy in childhood: comparison with conventional clinical, labora- 
tory, and imaging approaches. J Clin Endocrinol Metab 2001; 86: 4644-8.

10. Amrikachi M, Ponder TB, Wheeler TM, Smith D, Ramzy I. Thyroid fine-needle aspiration biopsy in children and adolescents: experience with 218 aspirates. Diagn Cytopathol 2005; 32: 189-92.

11. Hamburger JI, Husain M, Nishiyama R, Nunez C, Solomon D. Increasing the accuracy of fine needle biopsy for thyroid nodules. Arch Pathol Lab Med 1989; 113: 1035-41.

12. Park IA, Ham EK. Fine needle aspiration cytology of thyroid nodules: assessment of diagnostic accuracy and evaluation of each cytologic diagnosis. Korean J Cytopathol 1999; 10: 43-53.

13. Kim HJ, Jung PJ. Diagnostic value of fine-needle aspiration cytology in the operative management of thyroid nodules. J Korean Surg Soc 2000; 59: 590-5.

14. Kim SM, Lee KY, Kim SJ, Cho YU, Shin SH, Kim KR, Woo ZH. Correlation and the necessity of fine needle aspiration cytology and frozen section biopsy. J Korean Surg Soc 2002; 62: 187-91.

15. Sohn JH, Chae SW, Cho EY, Kim EJ. Diagnostic correlation and accuracy between fine needle aspiration cytology and histopathologic examination. Korean J Cytopathol 2003; 14: 53-9.

16. Kim ES, Nam-Goong IS, Gong GY, Hong SJ, Kim WB, Shong YK.
Postoperative findings and risk for malignancy in thyroid nodules with cytological diagnosis of the so-called "Follicular neoplasm". Korean J Intern Med 2003; 18: 94-7.

17. Yang GC, Liebeskind D, Messina AV. Should cytopathologists stop reporting follicular neoplasms on fine-needle aspiration of the thyroid? Cancer 2003; 99: 69-74.

18. Baloch ZW, Fleisher S, LiVolsi VA, Gupta PK. Diagnosis of "follicular neoplasm": a gray zone in thyroid fine-needle aspiration cytology. Diagn Cytopathol 2002; 26: 41-4.

19. van Hoeven KH, Kovatich AJ, Miettinen M. Immunocytochemical evaluation of HBME-1, CA 19-9, and CD-15 (Leu-M1) in fine-needle aspirates of thyroid nodules. Diagn Cytopathol 1998; 18: 93-7.

20. Eom TI, Choi JW, Min SK, Lee MJ, Park CY, Park SW, Lee BW, Kim LS. Diagnostic feasibility of galectin-3 for suspicious malignant thyroid nodule in preoperative fine-needle aspiration cytology. J Korean Surg Soc 2004; 66: 462-6.

21. Choi YL, Kim MK, Suh JW, Han J, Kim JH, Yang JH, Nam SJ. Immunoexpression of HBME-1, high molecular weight cytokeratin, cytokeratin 19, thyroid transcription factor-1, and E-cadherin in thyroid carcinomas. J Korean Med Sci 2005; 20: 853-9. 